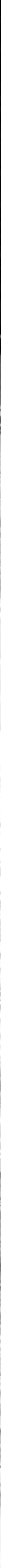




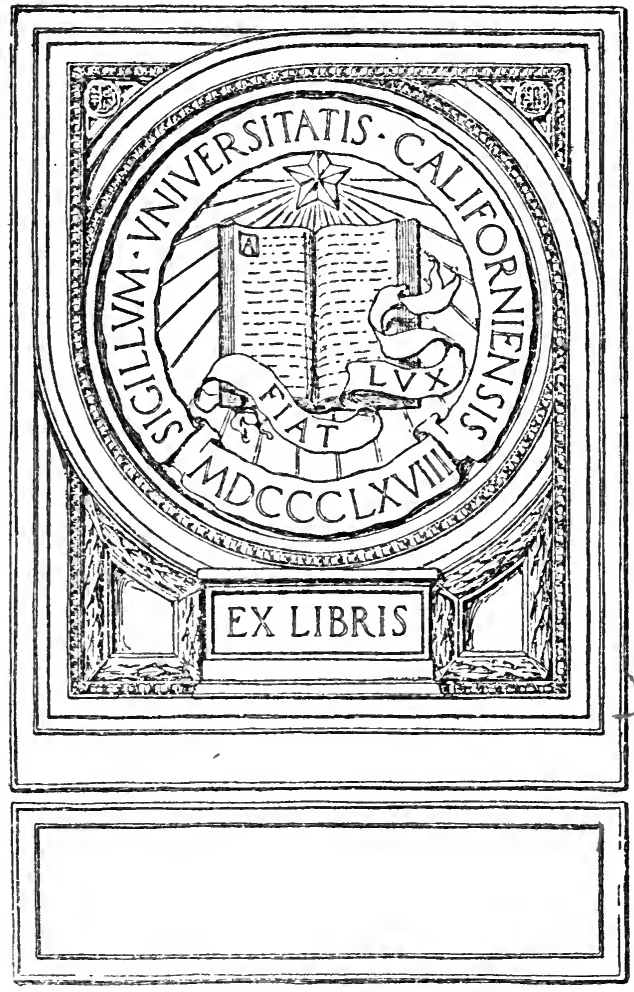


Digitized by the Internet Archive in 2007 with funding from

Microsoft Corporation 



\section{WHAT \\ EVERY MOTHER SHOULD KNOW \\ About ber Infants and Young Children}

$\mathrm{BY}$

Charles Gilmoré Kerley, M. D.

PROFESSOR OF DISEASES OF CHILDREN N. Y. POLYCLINIC MEDICAL SCHOOL AND HOSPITAL

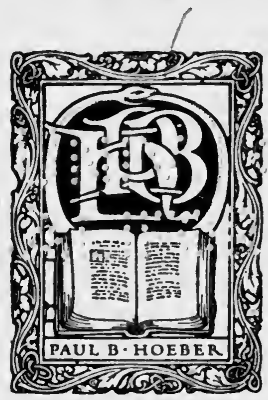

NEW YORK

PAUL B. HOEBER

$67-69$ EAST 59TH STREET

I 9 I 5 


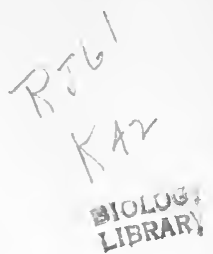

COPYRIGHT, I9I 5

By PAUL B. HOEBER

Published, June I9I5

Printed in the United States of America 


\section{PREFACE}

This pamphlet was prepared at the suggestion of a child's welfare organization. Its purpose is to place in the hands of the mother of moderate means, concise, readily understood and practical instructions for the care of their infants and young children.

Charles Gilmore Kerley.

I32 W. 8 I st Street,

May, I9I 5 . 



\section{CONTENTS}

PAGE

I. HYGIENE • • • • • • • . • • . • . 9

The Baby's Requirements . . . . . . . . 9

Sleep . • . . . . . . . . . . . . 9

Clothing Required at Birth. . . . . . . . 10

At Six Months . . . . . . . . . . . 13

At the First Year . . . . . . . . . . 13

The Out of Door Clothing . . . . . . . 15

The Bowel Function. . . . . . . . . 15

Fresh Air . . . . . . . . . . . . is

Airing in Cold and Inclement Weather . . . . 17

The BAth . . . . . . . . . . . . . 17

Bathing • . . . • . • . . • . . . . 19

Sponge Bath . . . . . . . . . . . . 19

Sponging on Hot Days . . . . • . . . . 19

Sponging for Prickly Heat . . . . . . . . 19

II. MATERNAL NURSING . . . . . . . . 2 I

The Diet . . . . . . . . . . . . . 2 I

Bowel Evacuation . . . . . . . . . . $2 \mathrm{I}$

Washing the Nipples . . . . . . . . . $2 \mathrm{I}$

Nursing Hours . . . . . . . . . . . 23

Regularity in Nursing . . . . . . . . . 23

Signs of Successful Nursing . . . . . . . 23

Failure of the Breast Milk . . . . . . . . 25

Conditions Under Which the Mother Should Not

Nurse . . . . . . . . . . 25 


\section{Contents}

III. ARTIFICIAL FEEDING

PAGE

Care of the Milk After Delivery . . . . . . 29

Bottle and Nipples. . . . . . . . . . 29

How to Clean the Bottles . . . . . . . . 29

The Care of the Nipples . . . . . . . . 29

Details for the Preparation of the Food . . . $3 \mathbf{I}$

How to Prepare the Food . . . . . . . $3 \mathbf{I}$

Heating the Milk . . . . . . . . . . . 33

IV. FOOD FORMULAS FOR WELL INFANTS . . 35

V. FEEDING FROM FIRST TO SIXTH YEAR . . . 4I

From the Twelfth to the Fifteenth Month; Five

Meals DaIly . . . . . . . . . . . $4 \mathrm{I}$

From the Fifteenth to the Eighteenth Month;

Four Meals Daily . . . . . . . . . 43

Sample Meal . . . . . . . . . . . . 45

From the Eighteenth to the Twenty-Fourth

Month; Four Meals DaILY . . . . . . 45

Sample Dinner . . . . . . . . . . . 47

From the Second to the Third Year; Three Meals

DAILY . . . . . . . . . . . . . . 49

From the Third to the Sixth Year . . . . . 5I

VI. DIET AFTER THE SIXTH YEAR . . . . . 57

Cooking of Vegetables. . . . . . . . . . 57

The Use of Sugar . . . . . . . . . . 57

VII. DENTITION . . . . . . . . . . . . 6r

The Teeth. . . . . . . . . . . . . 6I

The Permanent Set. . . . . . . . . . 63

Care of the Teeth . . . . . . . . . 63

VIII. AILMENTS . . . . . . . . . . . . 65

Sudden Attacks of Vomiting . . . . . . . 65 


\section{Contents}

PAGE

Persistent or Chronic Vomiting; Habitual Regurgitation

Diarrhea

Constipation . . . . . . . . . . . . 67

Constipation in Older Children . . . . . . 69

The Diet . . . . . . . . . . . . . 7 1

WORMS • . . . . . . . . . . . . . $7 \mathrm{I}$

The Round Worm . . . . . . . . . . 73

The Thread Worm . . . . . . . . . 73

The Tape Worm . . . . . . . . . . . 73

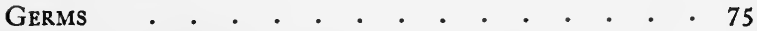

IX. FIRST AID TO THE BABY . . . . . . . 79

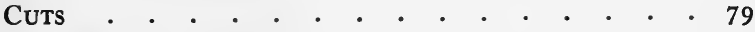

BRUISES AND BUMPS . . . . . . . . . 79

SPRAINS •

BURNS . . . . . . . . . . . . . . 79

Bites of Animals . . . . . . . . . . . 8I

BITES OF INSECTS . . . . . . . . . . . . 8I

FEVER . . . . . . . . . . . . . . . $8 \mathrm{I}$

Colic . . . . . . . . . . . . . . 8 I

Convulsions . . . . . . . . . . . . . 83

EARAche . . . . . . . . . . . . 83

NOSE-BLeEd . . . . . . . . . . . . 83

Foreign Bodies Swallowed . . . . . . . . 85

Foreign Bodies in Nose and Ear . . . . . . 85

Prickly Heat . . . . . . . . . . . 85

Croup . . . . . . . . . . . . 85

Sore Throat . . . . . . . . . . . 87

The Swallowing of Poisons . . . . . . . 87

X. GenERAL INSTRUCTIONS . . . . . . . . 89

How to Give an Enema . . . . . . . . . 89 


\section{Contents}

HOW TO CLEANE THE EYES PAGE

How to Cleanse the Eyes . . . . . . . . . 89

How to Cleanse the Baby's Nose . . . . . . 89

How to Syringe the Ears . . . . . . . . 9I

XI. GENERAL CONSIDERATIONS . . . . . . 93

WEIGHT •. . . . . . . . . . . . . 93

Vaccination . . . . . . . . . . . . 95

The Baby Basket . . . . . . . . . . 95

Kissing the Baby . . . . . . . . . . . 95

Flies and Mosquitoes . . . . . . . . . 97

Habits . . . . . . . . . . . . . . 97

Good Habits . . . . . . . . . . . 97

Bad Habits . . . . . . . . . . . 97

XII. DONT'S . . . . . . . . . . . . . . I0I

XIII. FORMULAS • . . . . . . . . . . 105

Barley Water . . . . . . . . . . . 105

Rice Water . . . . . . . . . . . . IO5

EgG WATER . . . . . . . . . . . . . 105

Beef, Mutton or Chicken Broth . . . . . 105

SCRAPED BeEF . . . . . . . . . . . . 105

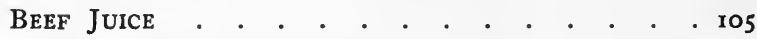

OAtmeal Jelly . . . . . . . . . . . . 107

WHEY . . . . . . . . . . . . . . 107

JUNKET • • • • • • • • • • • • • • 107 


\section{WHAT EVERY MOTHER SHOULD KNOW}





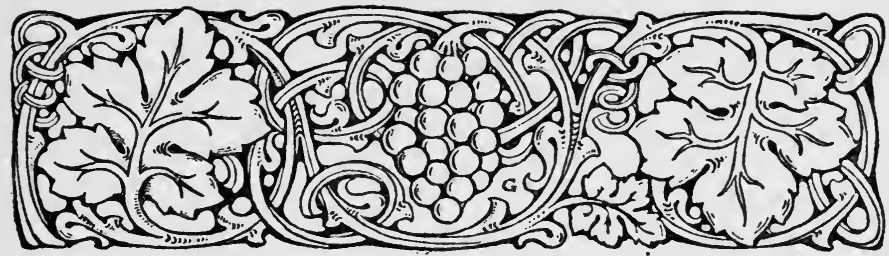

\section{WHAT EVERY MOTHER SHOULD KNOW}

I

HYGIENE

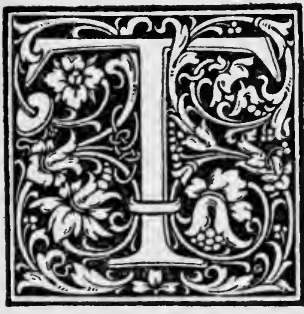

HE baby's actual requirements are few. He demands regularity in feeding either from the breast or bottle, a cleansing bath once daily, sponging once daily, fresh air, adequate sleep and suitable clothing. The baby should become habituated to system in all things that relate to his care and management.

THE BABY'S REQUIREMENTS

Sleep. A great deal of sleep is required by young babies. Until the child is three months old, he requires from twenty to twenty-two hours' sleep daily. 
Notes 
From the sixth month to the twelfth month the child should sleep from 6 P. M. to 6 A. M. without interruption other than for feeding or nursing at IO P. M. At the sixth month there should be a two-hour nap in the morning and one-hour nap in the afternoon. At one year of age one and one-half hour nap in the morning and one-hour nap in the afternoon answers. From the eighteenth to the twenty-fourth month one nap daily at midday is sufficient. An after-dinner rest of one and one-half hours should be continued until the child is six years old.

Clothing Required at Birth. The infant at birth requires practically the same clothing, winter or summer, three flannel bands, to be torn the desired length and width according to the size of the baby. This allows for a band in use, one to be laundered and one for emergency. The band is sewed on every day, after baby's bath. Have the needle ready for use in a small cushion especially for the purpose, and be sure to replace the needle when finished. We are very certain if the band is put on in this way that baby is not crying because pins are sticking in him.

Three silk and wool (or cotton and wool) shirts, high neck and long sleeves (lighter weight for a summer infant).

Three dozen cotton diapers.

Three flannel slips with button and button holes 
Notes 
on each shoulder. This type of garment prevents unnecessary handling of the child.

Six plain muslin slips.

At Six Months. From the third month on, according to the season, the child may be put in short clothes. The little slips can be cut short and a few new ones added. Eight in all are sufficient.

Three stockingette night slips, one easily washed every morning.

Three flannel petticoats, and stockings to cover the legs, as they have been kept very warm up to this time. In winter a silk and wool (or cotton and wool) stocking is advisable. A woven band is now used instead of the strips of flannel. The shirts are the same, except if the summer months have arrived the baby needs low neck cotton shirts instead of woolen ones.

The number of diapers the baby requires should now begin to diminish, for at regular intervals he is held on a small chamber to urinate. If his bowels move regularly he will seldom have a soiled napkin.

At the First Year. At about this age the child will begin to stand, and he must have shoes to support his ankles. Rompers will give him freedom and save on the laundry. As soon as he is sufficiently trained, (about i 8 months) drawers should replace the diapers.

Laced shoes are best for a walking child, but can- 
Notes 


\section{Hygiene}

not be procured for a small baby. When out of doors in winter the child should have his ears well covered, and a bonnet with an interlining should be used. A thin sweater is a convenient garment to use under the coat on very cold days. The child should never go out when the thermometer is under $15^{\circ} \mathrm{F}$. A fine piece of cheese-cloth may be made to fit the baby carriage, fastened on the hood, and this will guard against dust and the high winds.

The Out of Door Clothing is dependent entirely upon the season of the year and with the sudden changes which take place in the climate definite rules can not be laid down. Mothers are obliged to rely upon their own judgment, or that of experienced friends. As a general proposition it may be said that infants are very apt to be overclad, particularly during the hot weather.

The Bowel Function. It is necessary that the baby have one, or better, two stools daily. The normal stool is smooth and yellow. If barley water is used, the stool is made much darker. Infants on the breast will often have several stools a day and remain well. Frequent stools in bottle-babies always call for the attention of a physician.

Fresh Air. Fresh air is very necessary to growing children. This, in our modern dwellings, is best supplied through the open windows. A safe means of ventilation is in the use of a "window board." A 
Notes 
plain one-inch board is sawed the width of the window frame and placed under the raised window in the lateral frame groove resting upon the sill. This raises the top of the lower sash above the bottom of the upper one leaving a space between through which the air enters with the current directed upwards. The board may be four or six inches wide.

The open fireplace is an ideal means of ventilation but these are not to be found in many dwellings.

I Airing in Cold and Inclement Weather. When it is very cold and on stormy days, when the baby can not safely be taken out of doors, give an indoor airing. Dress him as if for out of doors, place him in the baby carriage, or in a clothes basket and allow him to rest in a room the windows of which are wide open.

\section{THE BATH}

As soon as the cord has fallen and the navel healed the baby is ready for the bath. This should be carried out in a warm room, $75^{\circ}$ to $80^{\circ} \mathrm{F}$. Castile soap should be used and the water should be luke warm, $95^{\circ}$ to $100^{\circ} \mathrm{F}$. The baby should be placed entirely in the water excepting the head and while one hand supports the head, the other is used in washing the child. Sponges should not be used. Soft old linen answers best as a washing medium. The baby should remain two or three minutes in the 
Notes 
water, when he is removed and placed in a large bath towel and dried. The bath may be given in the morning or evening. In the majority of instances it is most convenient to give the bath in the evening before the six o'clock feeding.,

\section{BATHING}

Sponge Bath. This simply means washing the baby, using warm water, castile soap and old linen as a wash cloth. The room should be warm and free from draughts and the child kept covered with a blanket during the procedure.

Sponging on Hot Days. When the weather is very hot, two or three spongings a day will help the baby to bear the heated term. The water may now be used as cool as it runs from the faucet. Five minutes is sufficiently long for the sponging.

I Sponging for Prickly Heat. Prickly heat is very annoying to many babies during the hot weather. This will be appreciably relieved by adding one tablespoonful of bicarbonate of soda to a quart of water and sponging the entire body for ten minutes. 
Notes 


\section{MATERNAL NURSING}

BABIEs at the breast very seldom suffer from summer diarrhea. Three to four thousand infants under one year of age die in Greater New York from intestinal diseases every year. These are nearly all bottle fed. It will easily be seen how important it is for the baby to be nursed. In order to nurse the baby satisfactorily, certain rules of life should be followed by the mother.

The Diet. The mother may eat simple plain food. There is no article of food, however, that is absolutely excluded. Tea and coffee should be taken sparingly. The mother should drink milk (one quart daily is sufficient) and cocoa and partake plentifully of oatmeal and cornmeal gruel. One-half pint of milk and one-half pint of gruel at bed time should be taken and a glass of milk or malted milk in the middle of the afternoon will also be of use. Bowel Evacuation. The mother should have one bowel evacuation daily.

Washing the Nipples. Before nursing, the nip- 
Notes 
ples should be washed with boracic acid solution, one tablespoonful to the pint of water.

Nursing Hours. Babies at the breast do better on three-hour nursings during the day and four hours at night as follows: 6 A. M., 9 A. M., I 2 M., 3 P. M., 6 P. M., IO P. M., and 2 A. M. After the 3 rd month the 2 A. M. nursing should be discontinued.

Regularity in Nursing. Absolute regularity in nursing is necessary in order that the breast may better secrete the milk. The baby's digestion will be far better also if he is nursed at regular intervals.

Signs of Successful Nursing. The baby is satisfied and falls asleep at the breast or is content after nursing ten or twenty minutes. There are two or three soft yellow stools daily. There is a gain in weight of four to six ounces weekly.

When the nursing is unsatisfactory, the baby demands frequent nursings, remains long at the breast, cries, vomits or has colic after he finishes. He loses in weight or makes little or no gain. A physician should be consulted at once as many nursing errors may be corrected by very simple means. An examination of the mother's milk may find it too weak or too strong or deficient in quantity, errors which may be easily corrected. Weighing the baby (with the clothes on) before and after nursings gives correct information as to the amount the baby gets at one nursing. 
Notes 
Failure of the Breast Milk. When the breast milk begins to fail, it does not mean that the baby must be weaned. It is now possible to supplement the breast feedings by the bottle. From two to four breast feedings may be given daily; for the other feedings, a modified cow's milk mixture (page 35 ) is used.

When the mother can not nurse the baby satisfactorily twice a day it is better to wean him.

Conditions under which the Mother should not Nurse. Those who have tuberculosis in any of its forms, epilepsy, syphilis, Bright's disease, or are rapidly losing weight should not nurse. Upon the advent of pregnancy nursing should be discontinued. When the milk fails or when the breast for any reason must be stopped, bottle feeding of cow's milk is begun. 
Notes 


\section{III}

\section{ARTIFICIAL FEEDING}

WhEN mother's milk fails in whole or in part, another means of feeding must be employed. We now have a choice of fresh cow's milk, condensed milk and the proprietary foods.

Fresh cow's milk supplies a means of feeding by the use of which we are best able to imitate the milk of the mother. In order to make cow's milk suitable it must be "modified," which means changing it by dilution with water and through the addition of sugar and lime water to make it resemble as closely as possible the milk of the mother.

The milk in the New York market is graded as follows :

Grade A - Raw milk, called certified milk.

Grade A - Pasteurized milk.

Grade B - Pasteurized milk.

Grade $\mathrm{C}-$ For cooking purposes (red top on bottle and white tag).

Milk is graded according to the care exercised in its production. (The difference between these 
Notes 


\section{Artificial Feeding}

various grades rests in the matter of care in the milk production.) Grade $\mathrm{A}$ - Raw (certified) is best for infant feeding.

Care of the Milk after Delivery. There is very little gained through the farmer producing a clean safe milk and keeping the milk iced until delivered if the mother allows it to stand in the hot air of the kitchen and perhaps exposed to flies and other insects. As soon as received the milk should be placed in the ice-box on the ice, not in the compartment below, where the vegetables and meats are kept. Here the milk should rest until such time in the morning as the mother is able to devote her attention to the preparation of the food.

Bottle and Nipples. Too much care can not be exercised in the care of the bottles. Unclean bottles and nipples have been the cause of many infants' deaths. The oval bottle without corners is the best. There should be as many bottles as there are feedings during the twenty-four hours.

How to Clean the Bottles. The bottles should be boiled once a day, scrubbed with a stiff bottle brush using hot borax water, two teaspoonfuls of borax to the pint of water. The bottles should then be placed in boiled cold water and kept there until used.

The Care of the Nipples. Only a nipple that may be easily turned should be used. After using, 
Notes 
the nipple should be turned and scrubbed with a stiff brush and borax water, two teaspoonfuls of borax to the pint of water. They should be boiled for a few minutes once a day.

For measuring purposes the mother should possess a one pint glass graduate which is a measuring glass marked in ounces, and a one ounce cream dipper (Chapin).

Details for the Preparation of the Food. With bottles and utensils previously cleaned the next step is for the mother to wash her hands with soap and water. The next duty is to drive away flies from the field of operation. They should never be allowed to rest on any feeding utensil. The use of various fly catching devices and the vigorous use of the "fly swatter" are very discouraging to the fly. With hands clean and utensils and bottles clean, the milk, water, sugar and lime water or barley water are mixed according to instructions which the mother may have received from the physician or nurse; or the formulas which follow (page 35) may be brought into use.

How to Prepare the Food. The formula, we will assume, calls for milk, or top milk, water, milk sugar and lime water. The milk is measured first. Milk sugar is difficult of solution in cold water, the required amount is best dissolved in a small portion of hot water. This sugar solution is then 
Notes 
added to the spring water or boiled hydrant water in sufficient amount to make the quantity called for, and mixed with the milk and lime water. The food now prepared is apportioned for the day's feeding, using as many bottles as there are feedings. Nonabsorbent cotton should be used instead of corks.

If barley water or any other cereal decoction is called for, that must previously be made and allowed to cool.

Heating the Milk. During the hot months it is usually advisable to heat the milk before using. Bringing it to the boiling point and maintaining it at this temperature for five minutes is all that is required. This is sufficient to kill bacteria or whatever germ life may be present; at the same time the milk is less liable to sour in the event of the ice becoming scanty.

The milk formulas which are to follow are arranged for the average well baby and will answer for many infants. There will be infants, however, who will not thrive on the formulas given. On account of some peculiar or unusual condition it will be necessary to use special or unusual methods in making the food suitable for the child. In all cases in which a baby does not thrive a physician should be consulted. 
Notes 


\section{IV}

\section{FOOD FORMULAS FOR WELL INFANTS}

IN using cow's milk for infant feeding the milk is allowed to stand in the quart bottle on the ice for five hours.

The top I 6 ounces are then dipped off with a one ounce cream dipper. If a dipper is not available the top I 6 ounces may be carefully poured out of the bottle. The poured off top I 6 ounces is the milk used until the third month; after this age larger amounts must be poured or dipped from the top.

The following formulas are suggested for the various ages noted:

FROM THE THIRD TO THE TENTH DAY

Milk (top 16 oz.) $\ldots \ldots \ldots \ldots \ldots \ldots \ldots \ldots \ldots, 3$ ounces

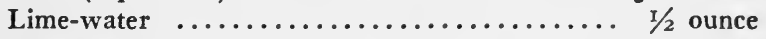

Milk-sugar .................... I ounce

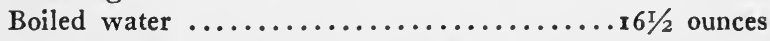

Nine feedings in twenty-four hours; $1 \frac{1}{2}$ to 2 ounces at twohour intervals during the day and three-hour intervals at night.

FROM THE TENTH TO THE TWENTY-FIRST DAY

Milk (top 16 oz.) $\ldots \ldots \ldots \ldots \ldots \ldots \ldots \ldots \ldots 6$ ounces

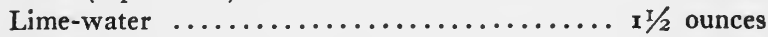

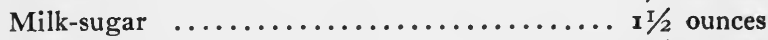

Boiled water $\ldots \ldots \ldots \ldots \ldots \ldots \ldots \ldots \ldots \ldots \ldots \ldots \ldots \ldots \ldots \ldots \ldots$ ounces

Eight feedings in twenty-four hours; 2 to $2 \frac{1}{2}$ ounces at two and 
Notes 
one-half hour intervals during the day and four-hour intervals at night.

\section{FROM THE THIRD TO THE SIXTH WEEK}

Milk (top 16 oz.) $\ldots \ldots \ldots \ldots \ldots \ldots \ldots \ldots \ldots$ ro ounces

Lime-water .......................2 ounces

Milk-sugar ....................... 2 ounces

Boiled water .......................... ounces

Seven feedings in twenty-four hours; 3 to 4 ounces at three-hour intervals during the day and four-hour intervals at night.

FROM THE SIXTH WEEK TO THE THIRD MONTH

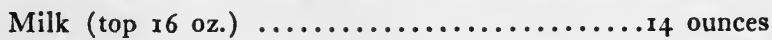

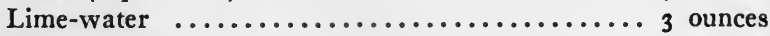

Milk-sugar $\ldots \ldots \ldots \ldots \ldots \ldots \ldots \ldots \ldots \ldots \ldots \ldots \ldots \ldots$ ounces

Boiled water ......................... ounces

Seven feedings in twenty-four hours; 4 to 5 ounces at threehour intervals during the day and four-hour intervals at night.

FROM THE THIRD TO THE FIFTH MONTH

Milk (top 18 oz.) $\ldots \ldots \ldots \ldots \ldots \ldots \ldots \ldots$ ounces

Lime-water ........................ 3 ounces

Milk-sugar ....................... 2 ounces

Boiled water $\ldots \ldots \ldots \ldots \ldots \ldots \ldots \ldots \ldots$.

Six feedings in twenty-four hours; 5 to 6 ounces at threehour intervals during the day and a feeding at ro P. M.

FROM THE FIFTH TO THE SEVENTH MONTH

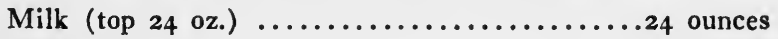

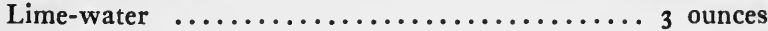

Milk-sugar $\ldots \ldots \ldots \ldots \ldots \ldots \ldots \ldots \ldots \ldots \ldots \ldots \ldots$ ounces

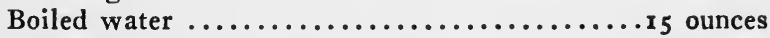

Five feedings in twenty-four hours; 6 to 7 ounces at fourhour intervals, the last feeding at ro P. M.

FROM THE SEVENTH TO THE NINTH MONTH

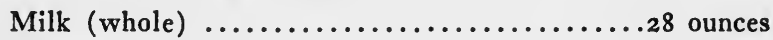

Lime-water ...................... 3 ounces

Milk-sugar .......................2 ounces

Barley water ........................ ounces

Five feedings in twenty-four hours; 7 to 9 ounces at fourhour intervals, the last feeding at ro P. M. 
Notes 
FROM THE NINTH TO THE TWELFTH MONTH

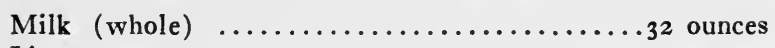

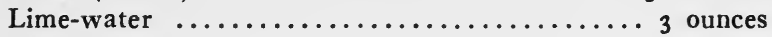

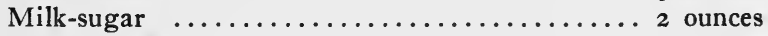

Barley water.$\ldots \ldots \ldots \ldots \ldots \ldots \ldots \ldots \ldots$ ro ounces

Five feedings in twenty-four hours; 8 to 9 ounces at four-hour intervals, the last feeding at ro P. M.

Barley water is made by cooking I ounce of Robinson's or Cereo barley flour in the called for water for thirty minutes. Boiled water is added to replace the amount lost in boiling. The barley water should not be hot when added to the milk and lime water. Milk sugar may be dissolved in hot barley water. Keep the nursing bottles on the ice after they are filled.

Convenient feeding hours are 6, Iค, 2, 6, Iо P. M. after 5 months of age. Strong vigorous infants may require stronger food than the above after the tenth month. It is not at all unusual for me to allow such infants a tablespoonful or two of farina or cream of wheat jelly (cooked two hours in water) before the IO A. M. and 6 P. M. feedings, with an ounce or two of the milk formula over it.

Occasionally at this age, 2 or 3 teaspoonfuls of beef juice mixed with bread crumbs are given before the 2 P. M. feeding. A piece of unsweetened zwieback or a crust of dried bread may be given after the bottle.

To obtain whole milk shake the bottle before use. 
Notes 


\section{V \\ FEEDING FROM FIRST TO SIXTH YEAR}

AfTer the twelfth month in well babies much freer feeding is required. The following schedules contain permissible articles for the ages indicated from which the mother will select suitable meals.

FROM THE TWELFTH TO THE FIFTEENTH MONTH; FIVE MEALS DAILY

7 A. M. Cornmeal, barley, rice or wheat jelly, one or two tablespoonfuls in 8 to ro ounces of milk. (The jelly is made by cooking the cereal for four hours the day before it is wanted and straining through a colander.) Stale bread and butter, zwieback and butter or wheatsworth biscuit.

9 A. M. The juice of one-half orange.

I I A. M. Scraped rare beef, one to three teaspoonfuls mixed with an equal quantity of bread and moistened with beef-juice. Or a soft boiled egg mixed with stale bread-crumbs; a piece of $\mathrm{zwie}$ back, and a half pint of milk.

(Scraped rare beef is best obtained from round 
Notes 
steak, cut thick and broiled over a brisk fire sufficiently to sear the outside. The steak is then split with a sharp knife and the pulp scraped from the fiber.)

$2: 30$ P. M. Beef, chicken or mutton broth with rice or stale bread broken into the broth. Six ounces of milk, if wanted. Stale bread and butter or zwieback and butter. Many children at the above age will take and digest apple-sauce and prune pulp; when these are given milk should be omitted.

6 P. M. Two tablespoonfuls of cereal jelly in 8 ounces of milk; a piece of zwieback. Stale bread and butter or Huntley \& Palmer breakfast biscuit.

Iо P. M. A tablespoonful of cereal jelly in 8 or Io ounces of milk.

FROM THE FIFTEENTH TO THE EIGHTEENTH MONTH; FOUR MEALS DAILY

7 A. M. Oatmeal, hominy, cornmeal, each cooked four hours the day before they are used. When the cooking is completed, the cereal should be of the consistence of a thin paste. This is strained through a colander, and upon cooling will form a mass of jelly-like consistence. Two or three tablespoonfuls of this should be served with milk and sugar, or butter and sugar, or butter and salt. Eight to ten ounces of milk as a drink. Zwieback or toast. 
Notes 
9 A. M. The juice of one orange.

I I A. M. A soft boiled egg mixed with stale bread-crumbs or baked potato. One tablespoonful of scraped beef mixed with stale bread-crumbs and moistened with beef juice. One tablespoonful minced white meat of chicken. Baked potato. A drink of milk. Zwieback or bran biscuit, or stale bread and butter.

Sample Meal. One tablespoonful of minced chicken mixed with baked potato. A drink of milk. Stale bread and butter.

$2: 30$ P. M. Chicken, beef or mutton broth, with rice or with stale bread broken into the broth. Custard, cornstarch, or plain rice pudding junket, stewed prunes, stewed apple. Bran biscuit and butter or stale bread and butter, wheatsworth biscuit.

6 P. M. Farina, cream of wheat, wheatena (each cooked two hours). Give from one to three tablespoonfuls, served with milk and sugar, or butter and sugar, or butter and salt. Drink of milk. Zwieback or stale bread and butter.

FROM THE EIGHTEENTH TO THE TWENTY-FOURTH MONTH; FOUR MEALS DAILY

7 A. M. Cornmeal, oatmeal, hominy (prepared as in the above schedule). Serve with butter and sugar, or milk and sugar or butter and salt. A soft-boiled egg every two or three days. Minced 
Notes 
chicken on toast occasionally. A drink of milk. Bran biscuit and butter or stale bread and butter.

When egg or minced chicken are given, cereal may be omitted or a small portion of cereal may be used.

9 A. M. The juice of orange.

I I A. M. Rare beef, minced or scraped; the heart of a lamb chop finely cut. Minced chicken. Baked potato. Spinach, asparagus, squash, strained stewed tomatoes, stewed carrots, mashed cauliflower. Baked apple, or apple-sauce. Stewed prunes. Stale bread and butter.

Sample Dinner. Lamb chop, baked potato. Stewed carrots, baked apple. Stale bread and butter.

After the twenty-first month well-cooked string beans may be given.

$2: 30$ P. M. Chicken, beef or mutton broth with rice or with stale bread broken into the broth. Custard, cornstarch, plain rice pudding, or junket. Bran biscuit and butter or stale bread and butter.

6 P. M. Farina or cream of wheat (each cooked two hours). Give from one to three tablespoonfuls, served with milk and sugar or butter and sugar or butter and salt. Drink of milk or malted milk or weak cocoa. Zwieback or stale bread and butter. Bennett's Wheatsworth Biscuit.

After the eighteenth month a large number of 
Notes 
children will have a better appetite and thrive more satisfactorily on three full meals a day. The breakfast is advised at 7:30 A. M. and the dinner at I 2 o'clock, and the supper at $5: 30$ P. M. At 3 P. M. or $3: 30$ P. M. a cup of broth and a cracker or toast or a drink of milk may be given if it does not take away the appetite for the evening meal.

FROM THE SECOND TO THE THIRD YEAR; THREE MEALS DAILY .

Breakfast: 7 to 8 o'clock. Oatmeal, hominy, cracked wheat (each cooked four hours the day before they are used), served with milk and sugar or butter and sugar. A soft-boiled egg, hashed chicken. Stale bread and butter. Bran biscuit and butter. A drink of milk.

At Io A. M. the juice of one orange may be given.

Dinner: I 2 o'clock. Strained soups and broths, rare beefsteak, rare roast beef, poultry, fish. Baked potato, peas, string beans, squash, mashed cauliflower, mashed peas, strained stewed tomatoes, stewed carrots, spinach, asparagus tips. Bread and butter. For dessert: Plain rice pudding, plain bread pudding, stewed prunes, baked or stewed apple, junket, custard or cornstarch.

Supper: $5: 30$ to 6 o'clock. Farina, cream of wheat, wheatena (each cooked two hours). Give from one to three tablespoonfuls served with milk 
Notes 
and sugar or butter and sugar or butter and salt. Drink of milk. Zwieback or stale bread and butter, wheatsworth biscuit. Twice a week custard, cornstarch or junket may be given. Occasionally malted milk or weak cocoa.

With very few exceptions three meals are best at this period. With three meals a child has a better appetite and much better digestion, and consequently thrives far better than one whose stomach is kept constantly at work. Some children, however, will require a luncheon at 3 or $3: 30 \mathrm{P}$. M. and will not do well without it. This is apt to be the case with delicate children, particularly those under two and one-half years of age. If food is necessary at this hour, a glass of milk and a wheatsworth biscuit or a cup of broth and zwieback will answer every purpose. Instead of the afternoon meal, the child may relish a scraped raw apple, or a pear. Fruit at this time is particularly to be advised if there is constipation. Children recovering from serious illness will require more frequent feeding.

FROM THE THIRD TO THE SIXTH YEAR

Breakfast: Cracked wheat, cornmeal, hominy, oatmeal (each cooked three hours the day before they are used). These may be served with milk and sugar, or butter and sugar or butter and salt. 
Notes 
A soft-boiled egg, scrambled egg. Bread and butter, bran biscuit and butter. A glass of milk.

Dinner: Plain soups, rare roast beef, beefsteak, poultry, fish. Potatoes, stewed with milk or baked. Peas, string beans, strained stewed tomatoes, stewed carrots, squash, white turnip, boiled onions, mashed cauliflower, spinach, asparagus tips, bread and butter. For dessert: Rice pudding, plain bread pudding, custard, tapioca pudding, stewed prunes, stewed apple, baked apple, raw apple, pears and cherries. Bread and butter.

Supper: Farina, cream of wheat (each cooked two hours). Give from two to three tablespoonfuls, served with milk and sugar, or butter and sugar or butter and salt. Zwieback or stale bread and butter. Bread and milk. Milk-toast. Scrambled eggs twice a week. Custard, or cornstarch. Bread and butter, wheatsworth biscuit. A glass of milk or malted milk or cocoa.

When the child has eggs for breakfast, they should not be repeated in any form for supper. Red meat should be given but three times a week. When the child has a chop for breakfast, he should have poultry or fish for dinner. At this age of great activity and rapid growth the child will often demand food between dinner and supper. Carefully selected fruit, such as an apple, a pear or a 
Notes 


\section{Feeding from First to Sixth Year 55}

peach, may be given at this time, supplemented by a wheatsworth biscuit or two, or by stale bread and butter, if it is found that their use does not interfere with the evening meal. 
Notes 


\section{VI}

\section{DIET AFTER THE SIXTH YEAR}

When the normal child has passed the sixth year the diet may be considerably expanded, approximating to that of the adult in variety; certain restrictions, however, are to be borne in mind. Fried foods should not be given; highly seasoned dishes, such as pie, rich puddings, gravies, and sauces are to be avoided. Salad with plain dressing may now be given. Wine and beer, coffee, and tea should never be given to children as a beverage.

Cooking of Vegetables. A point to be kept in mind in feeding children of this age, as well as those who are younger, is the proper cooking of vegetables. Everything in the line of green vegetables should be cooked until it can readily be mashed with a fork.

Vegetables should be cooked over a hot fire without a cover on the vessel used. They must not be allowed to stand in the water after the cooking is completed.

The Use of Sugar. Endeavor to use sugar scant- 
Notes 


\section{Diet After the Sixth Year}

ily, using only enough in puddings and stewed fruits to make them palatable. The sugar habit is readily acquired and is often of much harm. Cereals should always be cooked in water never in milk. 
Notes 


\section{VII}

\section{DENTITION}

Cutting of the teeth in well infants causes very little disturbance. The child may be restless for a few days, he keeps his fingers in his mouth and perhaps has a slight fever. If the usual food is continued, vomiting and diarrhea may be the outcome. It is better to reduce the diet by diluting the milk one-half with water and giving broths and gruels for a few days until the tooth is through the gum. If the stools are green and undigested, one or two teaspoonfuls of castor oil should be given.

\section{THE TEETH}

There are twenty teeth in the first or temporary set. The first teeth, the lower middle incisors usually appear between the sixth to eighth month. The two upper middle incisors appear next. Then the two upper lateral incisors and following these come the two lower lateral incisors. The first molars are cut between the twelfth and fifteenth month. The eye and stomach teeth are cut between the 
Notes 


\section{Dentition}

eighteenth and twenty-fourth month. The last four molars are cut between the twenty-fourth and the thirtieth month.

The Permanent Set. There are thirty-two teeth in the permanent set. The temporary teeth begin to fall out at about the sixth year and the permanent teeth begin to appear.

Care of the Teeth. For the first two years of life the mouth should be washed twice daily with a solution of boracic acid, one tablespoonful to the pint of water. This is best done by wrapping absorbent cotton around the index finger and dipping it into the solution when it may be applied with gentle friction to the gums and teeth.

After the second year a soft tooth brush and any simple tooth paste or powder may be brought into use and used in the morning and before retiring in the evening. 
Notes 


\section{VIII}

\section{AILMENTS}

\section{SUDDEN ATTACKS OF VOMITING}

ACUTE vomiting may be a symptom of different disorders. It may mean that there is simply an acute indigestion, the result of an over-loaded stomach or the use of some food substance which the baby should not have had, or it may mean the onset of an illness such as scarlet fever or pneumonia.

After an acute attack of vomiting, give no food for a few hours. Sips of water may do no harm. For the remainder of the day only barley water (page I05) or rice water (page 105) should be given. If there is fever or if the vomiting continues a physician should always be called. It is always well to give some laxative after an attack of vomiting. Castor oil usually will not be well retained and milk of magnesia may be substituted. The dose should produce a laxative effect and be from one to three teaspoonfuls.

Persistent or Chronic Vomiting; Habitual Regurgitation. There are many infants who vomit or regurgitate a portion of their food every day. In some there is pronounced vomiting; in others 
Notes 
what the mother calls "spitting up." This always means indigestion at first and later it becomes somewhat of a habit.

The bringing up of the food is usually due to too strong a milk mixture given at too frequent intervals, or perfectly satisfactory food given too frequently, or milk too rich in fat or containing too much sugar.

Babies who habitually vomit or regurgitate should be given shaken up milk (not the top removed) with barley water as a diluent, omitting the sugar. A ten-grain tablet of bicarbonate of soda added to the daily food allowance after the food is prepared will often be of much aid. Further, make the interval between the feedings an hour longer, increasing after a few days, the amount given at each time, one-half to one ounce, to make up for the amount lost by the less frequent feedings.

\section{DIARRHEA}

Diarrhea is always dangerous at any season of the year and should receive medical attention. In the event of a sudden attack, give one to two teaspoonfuls of castor oil, stop the milk feeding and give barley water (page ro5).

The barley water may be given in the same quantity as the milk mixture. This feeding should be continued until a physician is consulted.

Constipation. Owing to causes which need not 
Notes 
be discussed here constipation is one of the most frequent ailments of early life. Every infant, runabout child or adult should have at least one free evacuation of the bowels daily. In infants, two stools daily are better than one. A child should never be put to bed without having had an evacuation during the day.

In the breast-fed, constipation is not often troublesome. Constipation in the mother may be a cause and should be remedied through suitable diet for the mother, such as raw fruit and green vegetables, with little or no tea. For the baby, olive oil, two or three or more teaspoonfuls daily usually answers the purpose. Milk of magnesia is a simple and harmless means of relieving constipation in infants; from ten drops to a teaspoonful of milk of magnesia may be given.

In the bottle-fed: Instead of milk sugar, use cane sugar or malt sugar (dextri-maltose). In preparing the milk, lime water should be omitted, and milk of magnesia, one-half to two teaspoonfuls added to the entire formula after it is completed. Olive oil may also be given, one to two teaspoonfuls two or three times a day.

Constipation in Older Children. In constipation in older children the establishment of the habit of an evacuation at a certain time each day is of value. The best time is after breakfast; for a few days only, 
Notes 
a suppository or an enema of warm soap water may be used. This will help to establish a regular movement of the bowels at that time.

The Diet. Many children suffering from constipation will be entirely relieved by diet. To be avoided are dried bread, toast and zwieback. Potato may be given twice a week. Milk should not be given in large amount; I 2 to 16 ounces of milk daily is sufficient. Malted milk is laxative to most children and may be used once daily replacing cow's milk. Stewed fruits should be given freely. Raw fruits such as apple, pear, grapes and banana may be given. Between three and four o'clock in the afternoon is the best time to use raw fruits for constipation. When potato is not given, two green vegetables may be used for the midday meal. As bread stuffs, whole wheat bread, wheatsworth biscuit will be found valuable. In addition to the above, olive oil, one to two tablespoonfuls daily or liquid albolene (aromatic) in like amount may be used.

Like the younger child the runabout child should never retire for the night without an evacuation having taken place during the day.

\section{WORMS}

There are three varieties of worms commonly seen in children: the large round worm, the thread worm and the tape worm. 
Notes 
The Round Worm. Children under two years of age are rarely troubled with the round worm. The round worm is from five to eight inches in length and resembles the common earth worm.

The most usual symptoms of round worms are diarrhea alternating more or less with constipation and stomach ache. There may be loss of appetite or the child may be very hungry. Usually the presence of a worm passed in the stool gives the first knowledge of its presence.

The Thread Worm. The thread worms inhabit the rectum and the lower portion of the large intestine. They are like little pieces of white thread one-fourth to one-half inch in length. They cause a great deal of local itching and irritation, particularly at night.

The Tape Worm. Tape worms in children are not often seen in this country. The child with a tape worm may show no symptoms whatever or may have a great deal of abdominal discomfort. Sometimes there will be sharp attacks of diarrhea. Pieces of the worm are usually discharged which resemble pieces of flat white tape.

Worms can not be treated by the family. The medicine used and the local measures necessary must be under the immediate direction of a physician. Worm medicine and worm candy advertised in the press and sold in drug stores should not be used. 
Notes 
GERMS

What need has the mother to know about germs? She, of all persons should know because nearly all the illnesses of infant and child life are due to invisible bodies, some so tiny that the most powerful microscope fails to detect them.

The following is a list of some of the diseases which have been proven due to germs or bacteria:

Consumption (Tuberculosis),

Meningitis,

Cholera,

Typhoid fever,

Infantile paralysis,

Diphtheria,

Whooping cough,

Cholera Infantum,

Dysentery,

Summer diarrhea,

Grippe,

Pneumonia,

Bronchitis.

Scarlet fever, small-pox, measles, mumps, chicken pox and others are of germ origin, but the particular germ causing each disease has not been proven.

Boiling, sterilizing and the use of soap and hot 
Notes 


\section{Ailments}

water for scrubbing purposes together with sunlight and fresh air and the destruction of flies, mosquitoes and other insects are the great means of combating germ life. 
Notes 


\section{IX}

\section{FIRST AID TO THE BABY}

Cuts. Keep fingers, water, clothing, dust - everything away from the wound. Mix one teaspoonful of tincture of iodine with the same quantity of alcohol, and paint this solution on the skin about the wound, from the very edges of the wound to at least two inches away on all sides, provided of course that the part injured will permit of this wide application. Then apply a freshly ironed piece of linen and a bandage. This dressing must be kept in place.

Bruises and Bumps. Apply cloth wrung out in cold water. Change frequently.

Sprains. Wrap a bandage around the part and keep wet with cold water in frequent application. If the injured part is a lower extremity, keep it elevated on a plane with the body.

Cuts, bruises and sprains of consequence require the early attention of the family physician.

Burns. If the skin is merely reddened, apply vaseline or sweet oil on clean linen. If the skin is 
Notes 
blistered or charred, do not apply any oily substance. Sprinkle boric acid powder over the parts and cover with clean linen until the physician arrives.

Bites of Animals. Bites of animals are rarely serious. Hundreds of individuals are bitten by dogs and cats every year without other harm than that of the wound inflicted. Apply at once on old linen a solution of one teaspoonful of carbolic acid in one pint of water or one ounce of boracic acid in one pint of water. Keep this dressing wet on the wound until a physician is seen.

Bites of Insects. Bites of insects may be dangerous. Mosquitoes can transmit malaria and yellow fever. It is generally believed that the stable fly may transmit infantile paralysis. Insect bites although innocent of great harm, cause a great deal of discomfort through itching and temporarily disfigure the child. Frequent applications of Witch Hazel are helpful in relieving the patient.

Fever. The onset of sudden fever is to be met by a dose of castor oil, one to two teaspoonfuls, an enema (page 89) if there has been constipation and a sponge bath (page 19) with cool water. The sponging may be continued for fifteen to twenty minutes.

Colic. An attack of colic is best relieved by an enema (page 89) by giving sips or teaspoonful doses of quite hot water. A soda mint tablet dis- 
Notes 
solved in one ounce of hot water and given in teaspoonful doses every five minutes will relieve many cases. The food should be temporarily discontinued and water given. If the child has colic habitually it means that the food given needs the attention of a physician.

Convulsions. While awaiting the physician place the baby in a warm bath and rub the body vigorously while in the bath. If mustard is at hand add two teaspoonfuls to the water used. The great majority of convulsions are due to indigestion and constipation. Give the baby an enema as soon as possible, perhaps while in the bath. As soon as the baby can swallow give two teaspoonfuls of castor oil. For a few days following, a greatly reduced diet should be given.

Earache. Ist. Drop warmed sweet oil into the ear. Test your own ear first to insure its not being too hot.

2nd. Rest the affected side on a hot water bag.

3 rd. Syringe the ear (page 89) with water at I $10^{\circ} \mathrm{F}$. If a thermometer is not at hand have the water quite warm and test the heat of the water in your own ear before using.

Nose-bleed. The child should sit erect, not lie down. The nose should be firmly compressed between the thumb and finger for several minutes. The tips of the thumb and finger should touch the lower portion of the nasal bones. After the bleed- 
Notes 
ing is controlled in this way, a small piece of ice should be wrapped in a handkerchief and held against the affected side. Repeated hemorrhage usually means that an ulcer is present in the nostrils and needs active treatment.

Foreign Bodies Swallowed. Foreign bodies swallowed by infants and young children rarely cause harm. Do not give a laxative. Give starchy substances such as oatmeal, potato, cornmeal mush, substances which may form a semi-solid mass in the intestine in which the object swallowed may become imbedded and carried forward.

Foreign Bodies in Nose and Ear. A foreign body in either nostril may sometimes be removed by making pressure over the unobstructed nostril and then directing the child to blow the nose vigorously.

Substances not thus removed as well as foreign bodies in the ear should only be removed by a physician.

Prickly Heat. Prickly heat is best treated by sponge baths of bicarbonate of soda, one tablespoonful to two quarts of water. Do not rub the skin in drying. Several times a day dust the skin thoroughly with a powder composed of equal parts of powdered starch and oxide of zinc, obtained at the druggist's. Children with prickly heat should wear thin gauze or linen underwear. Wool should not be worn.

Croup. There are two kinds of croup, catarrhal 
Notes 
or spasmodic and diphtheritic or membranous croup.

Croup always calls for the immediate attention of a physician. While waiting for the doctor, give the patient a teaspoonful of Syrup of Ipecac to be repeated in I 5 minutes, if vomiting does not occur. The child is much relieved by vomiting, if the case is one of spasmodic croup. Steam inhalation from a croup kettle or a tea-kettle are of much service. Care must be exercised not to burn the child.

Sore Throat. A mother must never attempt to treat a sore throat in a child. Diphtheria usually begins with low fever and a slight sore throat. A physician should be called in every case of sore throat in a child. I could give many instances in which children have died with diphtheria because of neglected "home treated" sore throat.

The Swallowing of Poisons. Unfortunately children are sometimes given the wrong medicine or given some poisonous substance instead of the medicine intended. I have known children to swallow poisonous tablets and pills intended for adults. Under such circumstances the child should always be made to vomit. This can be done by "gagging" the child through forcing the clean index finger low in throat. If Syrup of Ipecac is at hand two teaspoonfuls may be given which will be sufficient to produce active vomiting. The physician must be called at once in all cases of poisoning. 
Notes 


\section{$\mathrm{X}$ \\ GENERAL INSTRUCTIONS}

\section{HOW TO GIVE AN ENEMA}

MAKe a suds of water and castile soap. Pour one pint water into the bag of a fountain syringe. Introduce the black rubber tip into the anus. Raise the bag two feet above the child's head and allow the water in part or entire to pass into the intestine.

\section{HOW TO CLEANSE THE EYES}

Dip clean absorbent cotton in boracic acid solution, teaspoonful to one glass of water (dissolved with hot water); the solution may be used cool or luke warm. Use a fresh piece of cotton for each eye.

HOW TO CLEANSE THE BABY'S NOSE

Wrap loosely a bit of absorbent cotton on a wooden toothpick. Dip the cotton in vaseline and with the baby's head held firmly introduce the cotton into the nostrils and through very gentle manipulation, remove the crusts and secretions that may have formed there. Use fresh cotton for each nostril. 
Notes

, 
HOW TO SYRINGE THE EARS

Necessary articles: A two quart fountain syringe and a small basin.

The child should be wrapped in a sheet with the arms bound to the side. He should rest on his back on the bed or couch. The basin protected by a towel is placed under the ear. Into the bag of the syringe is poured the solution to be used for the douching. The bag is held three feet above the child's head. The small black rubber tip is held about one-fourth inch from the orifice of the ear canal and the solution allowed to flow. The ear should be drawn slightly backward as this straightens the canal and allows of a freer flow of water. 
Notes 


\section{$\mathrm{XI}$ \\ GENERAL CONSIDERATIONS}

\section{WEIGHT}

IT is a part of baby's business to gain in weight and this is something that all well babies eventually must do. A definite weekly gain, however, is not necessary. Perfectly well babies will sometimes fail to gain for a month. During the hot weather, many infants make little or no gain but make up for it in the autumn.

Loss in weight even if slight but continuous should not be permitted and such infants or young children should be in the care of a physician.

The well baby should gain from four to six ounces weekly.

The weights of the average child at different ages are as follows:

At birth, 7 pounds, 8 ounces.

At 6 months, 15 pounds, 8 ounces.

At 9 months, I 8 pounds.

At I year, 20 pounds.

At 2 years, 27 pounds. 
Notes 
At 3 years, 3 I pounds.

At 4 years, 35 pounds.

At 5 years, 4I pounds.

\section{VACCINATION}

Vaccination against smallpox is very necessary. The best time for vaccination is from the third to the fifth month. After the vaccination the sore should be protected by a sterile bandage or old linen which has been boiled and dried.

Ignorant people may try to influence the mother against vaccination. The advisability of vaccination has been proven many times in different countries.

THE BABY BASKET

A convenient means of caring for a young baby while the mother is at work is in the use of an ordinary clothes-basket. The baby rests on a pillow or blanket and may be moved about with but little trouble.

KISSING THE BABY

Never kiss a baby on its mouth or allow your friend to do it. Kissing the baby on the hands is almost as bad for the baby's hand soon finds its way to his mouth. The common head cold, grippe, diphtheria, tuberculosis and other diseases very serious in nature may be transmitted to a child through kissing. 
Notes 


\section{FLIES AND MOSQUITOES}

Flies are a source of much greater danger than is usually appreciated and every effort should be made to destroy them. Through the means of the feet and legs of the fly, deadly disease germs may be transferred to the baby's food or feeding utensils. Tuberculosis, typhoid fever, diphtheria, infantile paralysis, summer diarrhea and many other diseases may be contracted through the agency of flies.

Malaria and yellow fever are transmitted through the mosquitoes.

It will thus be seen that both flies and mosquitoes are very dangerous and should not be allowed to come in contact with the baby or the food or feeding utensils.

A mosquito netting should be used to cover the crib and baby carriage.

\section{HABITS}

Good and bad habits are very readily acquired by infants and young children.

Good habits consist in the child taking his food at regular intervals, in sleeping at the appointed times, in resting quietly and amusing himself when awake.

Bad habits consist in demanding food between the regular feeding hours, in sleeping poorly at in- 
Notes 
definite times, in requiring constant attention when awake.

Sucking the thumb and finger and the use of a pacifier are bad habits, displacing the teeth, deforming the jaws and face. The use of the "hand-i-hold mit" obtained in most drug stores is a safe means of breaking the thumb-sucking and pacifier habit. Some children develop the habit of eating the wool from their blankets; others will place foreign bodies in the nose and ears.

Both boys and girls readily acquire the habit of manipulating the genitals with their hands or rubbing the legs together. This is a particularly vicious habit and requires immediate correction.

The prompt correction of all bad habits is very important. By keeping the genitals clean, masturbation is less liable to occur. In the use of proper clothing, right observation and discipline bad habits are readily corrected. In most cases the advice of the family physician will be necessary. 
Notes 


\section{XII}

\section{DON'TS}

Do not kiss the baby or allow your friends to do so.

Do not give soothing syrups or paregoric.

Do not give proprietary cough medicines.

Do not fail to secure the best milk you can afford to buy.

Do not allow flies to rest on feeding bottle or nipple.

Do not fail to wash the hands before preparing the food.

Do not neglect to properly cleanse the bottle and nipple.

Do not allow the milk bottle to remain uncovered or off the ice.

Do not fail to keep the food on the ice after it is prepared.

Do not feed the baby at irregular intervals.

Do not fail to change the napkin as soon as it is soiled.

Do not fail to protect the baby from flies and mosquitoes by suitable mosquito netting.

Do not give the baby a pacifier. 
Noies 


\section{Don'ts}

Do not allow the baby to go one day without a bowel movement.

Do not neglect the daily care of the mouth.

Do not excite the baby during or immediately after feeding.

Do not raise the baby without supporting the back.

Do not neglect to powder all folds of the skin.

Do not neglect to keep the ice-box clean and filled with ice. 
Notes 


\section{XIII}

\section{FORMULAS}

Barley Water. One heaping tablespoonful of Robinson's or Cereo barley to one pint of water. Cook 30 minutes and add water to make one pint.

Rice Water. One heaping tablespoonful of rice to one pint of water. Cook four hours and add water to make one pint.

Egg Water. The white of one egg, thoroughly beaten in one pint of cold boiled water, strain, add a pinch of salt.

Beef Mutton or Chicken Broth. Take one pound of meat free of fat. Cook for three hours in a quart of water. Strain and when the broth is cool remove the fat and add salt to flavor.

Scraped Beef. Broil round steak slightly over a brisk fire. Split the steak and scrape out the pulp.

Beef Juice. Cut round steak into pieces, size of a horse-chestnut. Place in a buttered pan in a hot oven and bake for 15 minutes. Remove the pan and press out the blood with a lemon squeezer, or broil round steak very rare; cut in small pieces, place 105 
Notes 
in a lemon squeezer or meat press and press out the blood, add a little salt.

Oatmeal Jelly. Oatmeal, four ounces; water, one pint; boil for three hours in a double boiler, water being added, so that when the cooking is completed a thin paste will be formed. This, while hot, is forced through a colander to remove the coarser particles. When cold, a semi-solid mass will be formed.

Whey. Put one pint of fresh milk into a saucepan and heat it lukewarm, not over $100^{\circ} \mathrm{F}$; then add two teaspoonfuls of Fairchild's essence of pepsin and stir just enough to mix. Let it stand until firmly jellied, then beat with a fork until it is finely divided, strain, and the whey, the liquid part, is ready for use.

Junket. To one pint of fresh milk add one tablespoonful of essence of pepsin or a junket tablet, and two teaspoonfuls of sugar. Allow it to stand over a fire until the temperature is $100^{\circ} \mathrm{F}$.; then add vanilla as a flavoring and allow it to stand until the curd is set, when it should be placed upon ice. 


\section{Short Talks with Young}

\section{Mothers}

\section{On the Management of Infants and Young Children}

By CHARLES GILMORE KERLEY, M.D.

Professor of Diseases of Children, N. Y. Polyclinic Medical School and Hospital; Attending Physician to the N. Y. Infant Asylum; Assistant Attending. Physician to the Babies' Hospital, N. Y.; Consulting Physician, New York Home for Crippled and Destitute Children; Consulting Pediatrist, Greenwich Hospital; Consulting Physican, Savilla Home, N. Y.

Second Edition, Revised and Enlarged. With 2I Illustrations. 345 pages. Cr. 8vo. \$1.oo net. By mail, \$I.Io

\section{SOME CRITICAL COMMENTS}

"It is full of practical suggestions and has evidently been written by a man who has had wide personal experience in the management of the nursery. It is singularly free from all theoretical bias.

"Every word that Dr. Kerley has to say on the subject of habits is worth attention and is useful not only for mothers, but for practitioners also, who are frequently consulted in such matters.

"The directions for the feeding of infants and young children are very simple and in accordance with the best modern principles.

"We highly commend the diet schedules which are drawn up for the children of from one year to six years of age."-London Lancet.

"... Clear, sensible, exhaustive, and interesting. It is not too large to be conveniently handled and the print is very clear."

The Criterion.

G. P. PUTNAM'S SONS, NEW YORK 



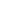


UNIVERSITY OF CALIFORNIA LIBRARY, BERKELEY

THIS BOOK IS DUE ON THE LAST DATE STAMPED BELOW

Books not returned on time are subject to a fine of $50 \mathrm{c}$ per volume after the third day overdue, increasing to $\$ 1.00$ per volume after the sixth day. Books not in demand may be renewed if application is made before expiration of loan period.

\section{PR 301927}

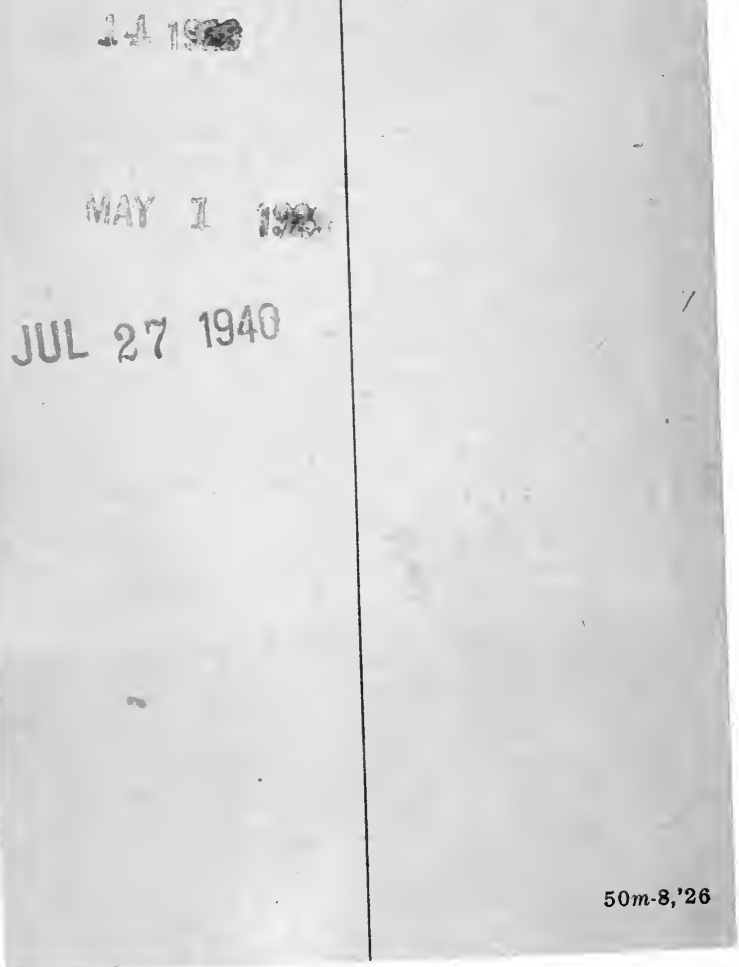




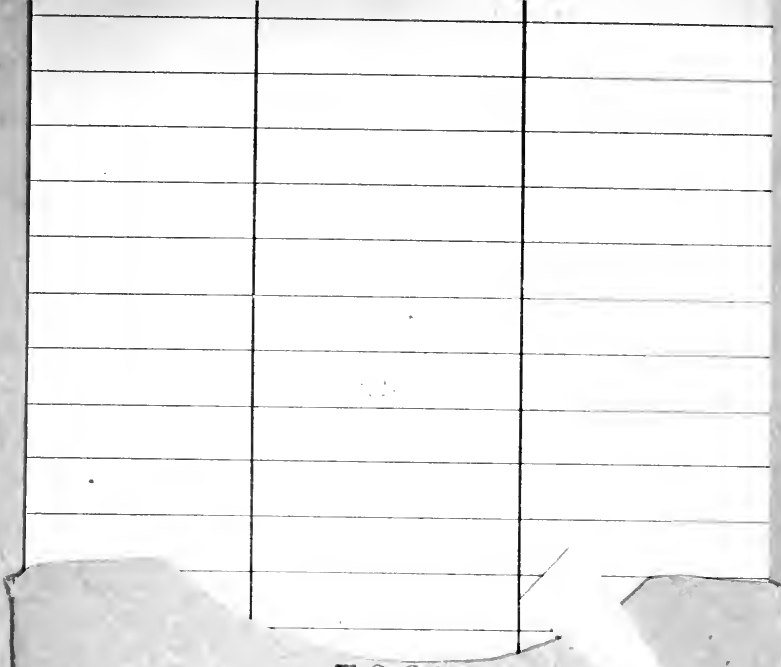

506510

Riṽ

IBKAR"

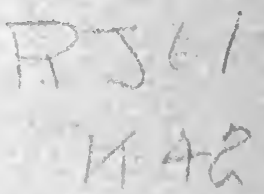

UNIVERSITY OF CALIFORNIA LIBRARY 


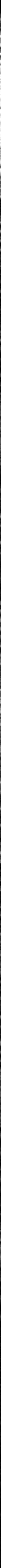

